\title{
Total Synthesis and Elucidation of Absolute Configuration of the Diterpene Tonantzitlolone
}

Christian Jasper, Rüdiger Wittenberg, Monika Quitschalle, Jasmin Jakupovic, Andreas Kirschning* 

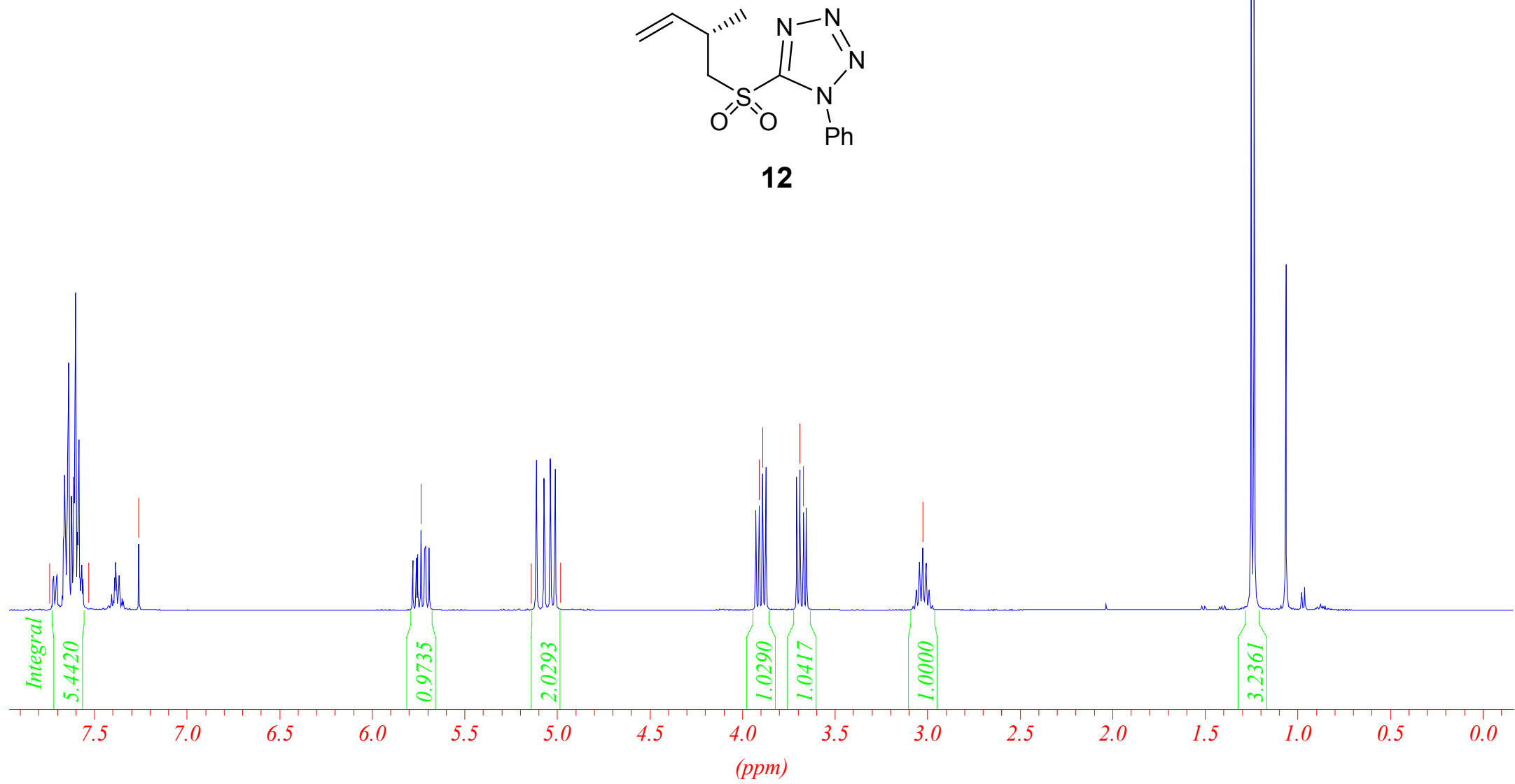


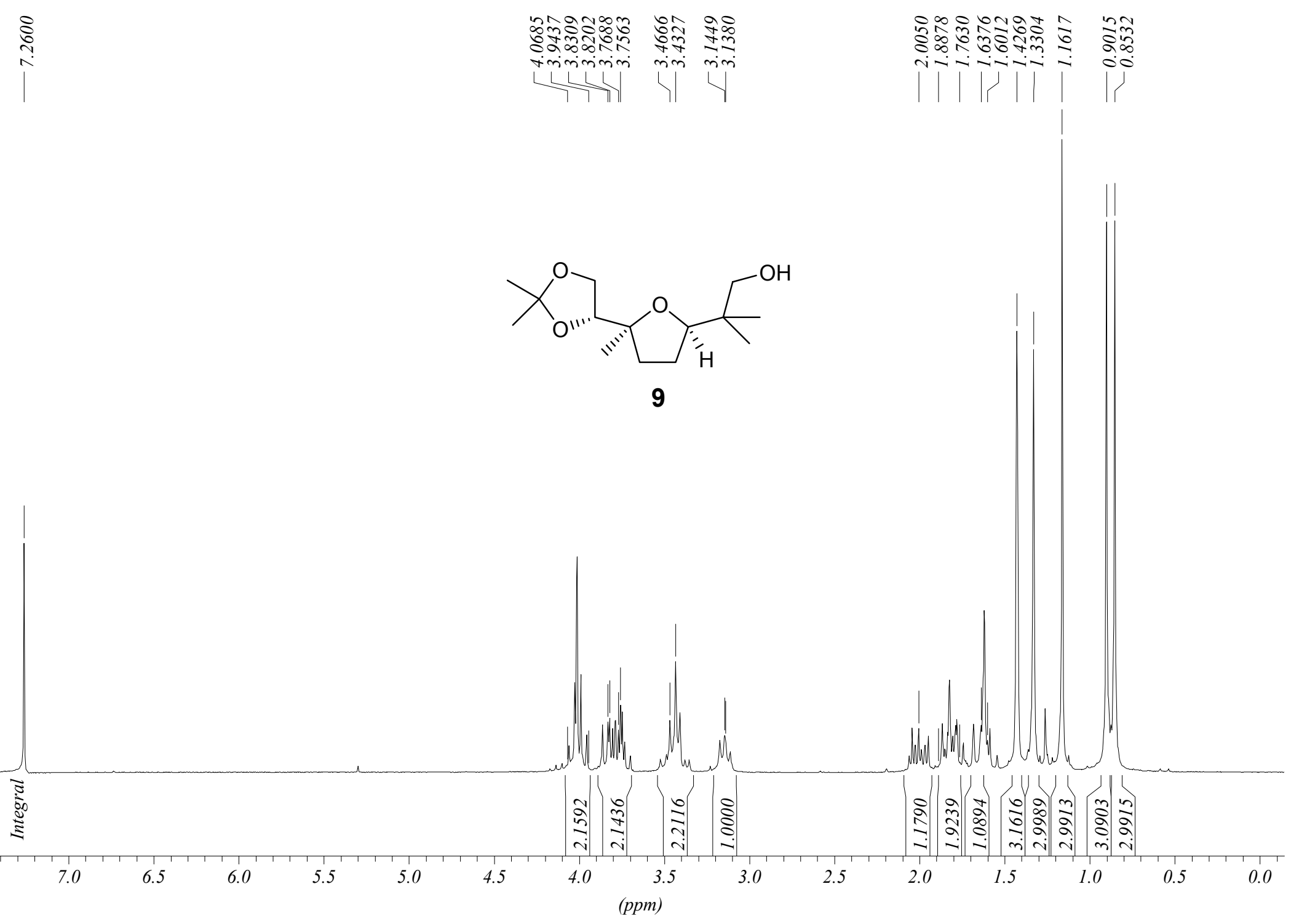




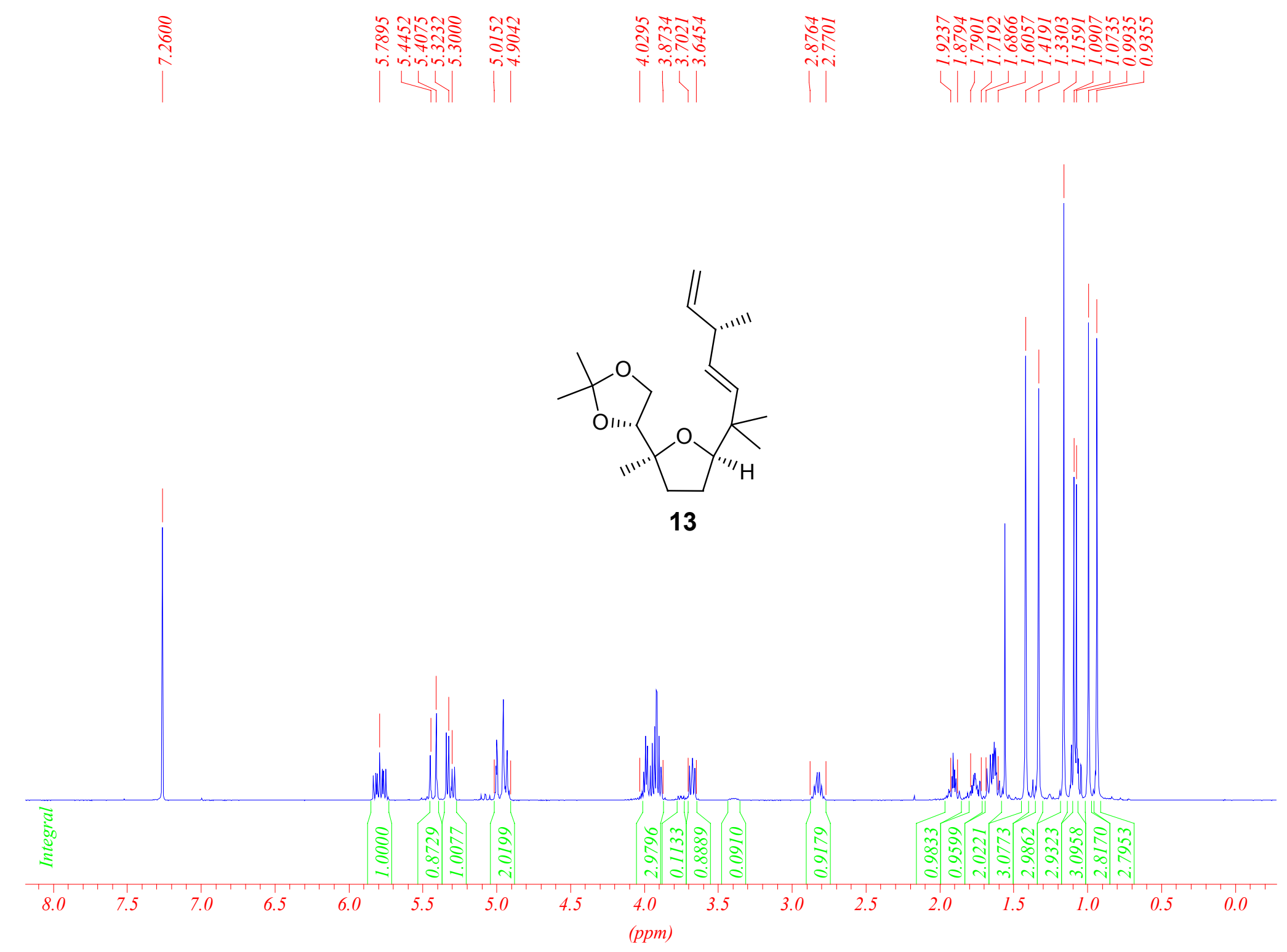




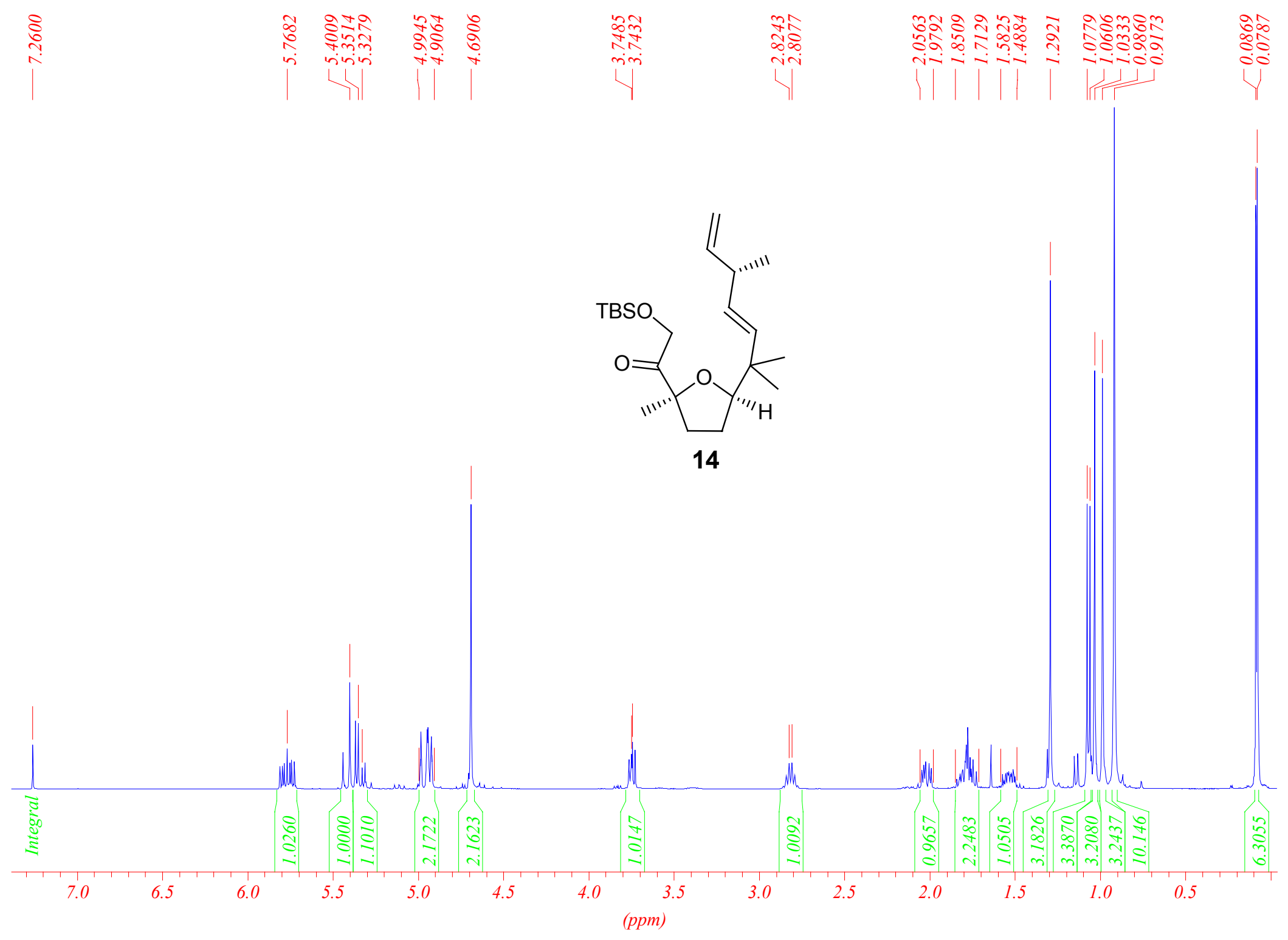




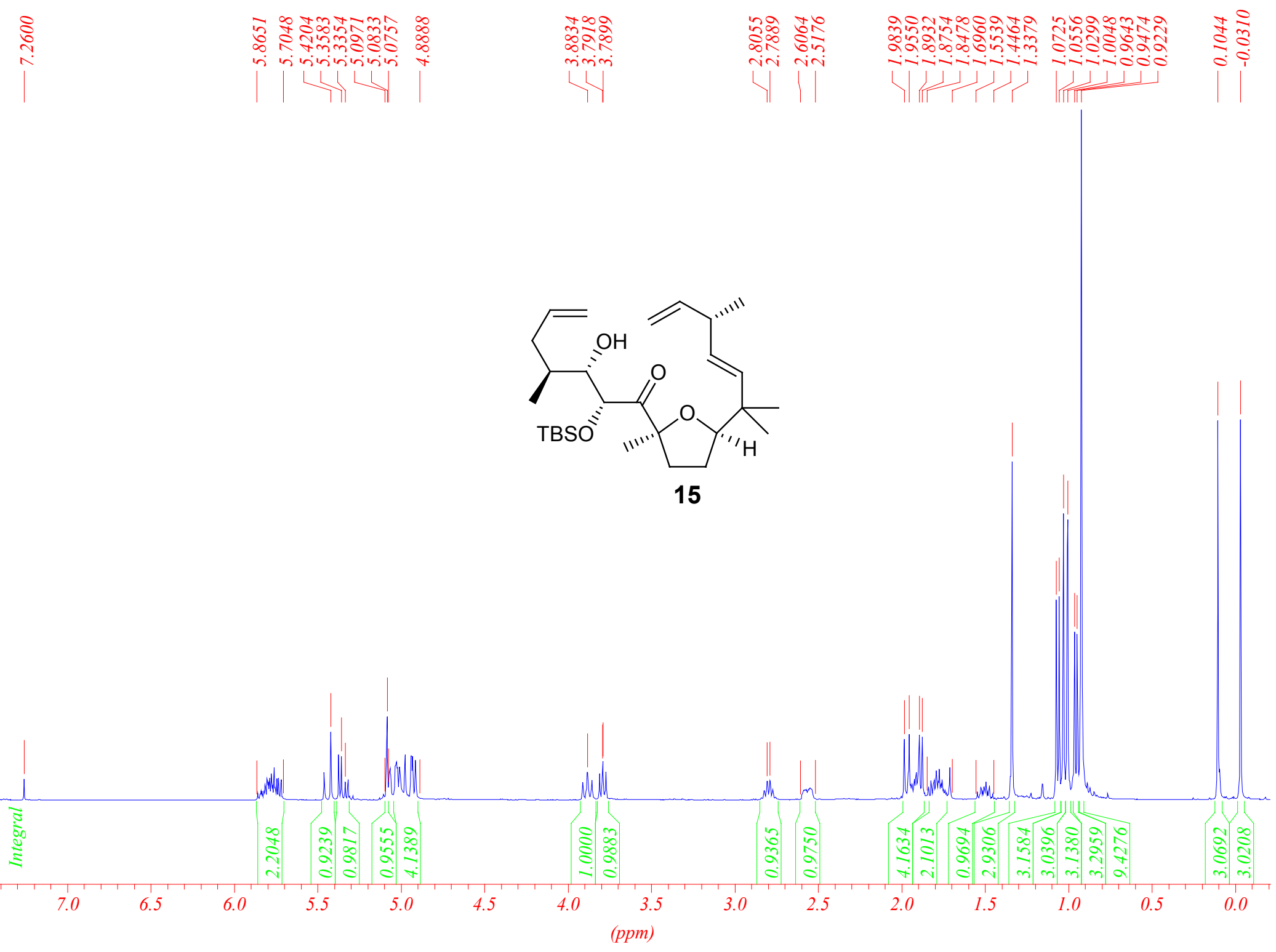




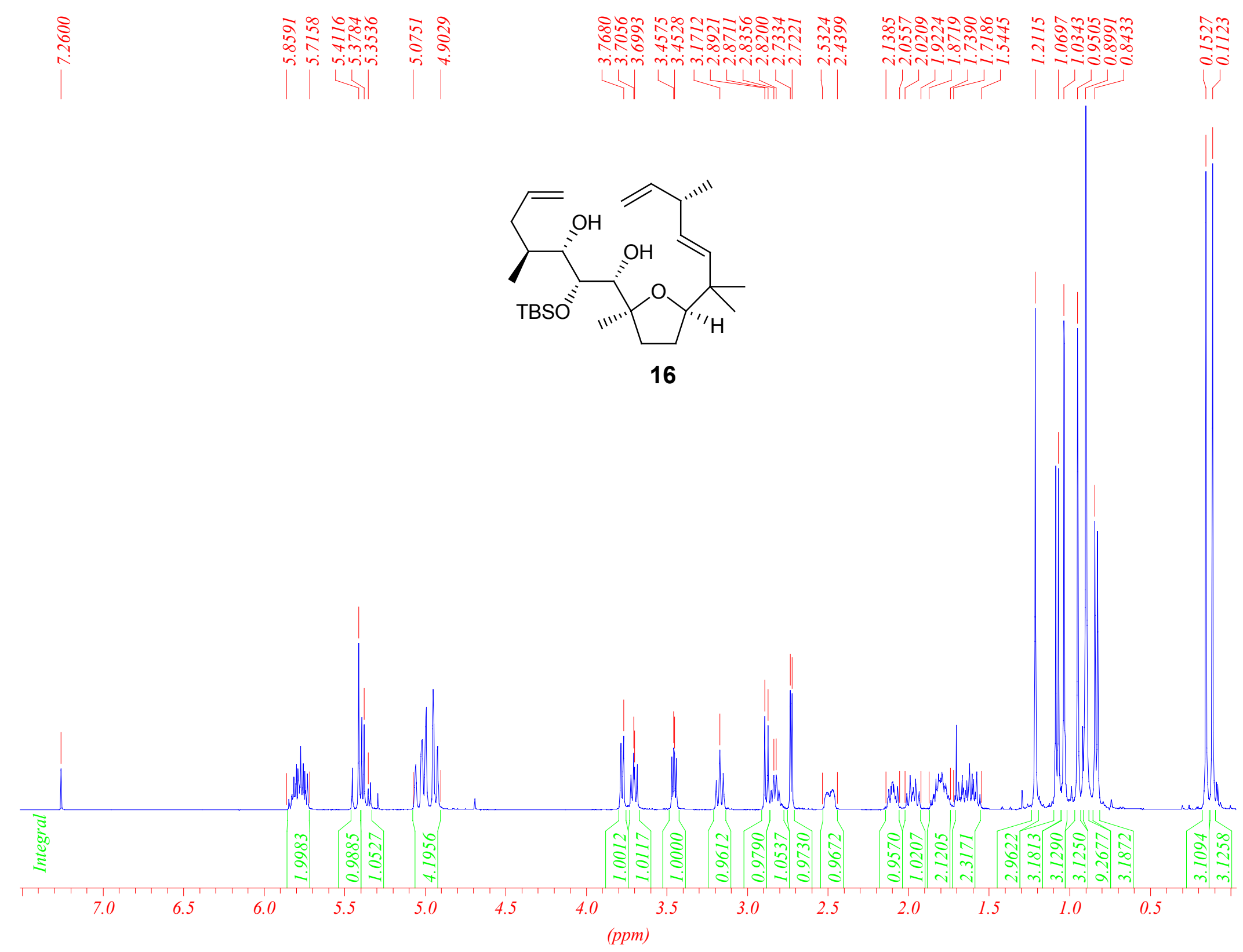




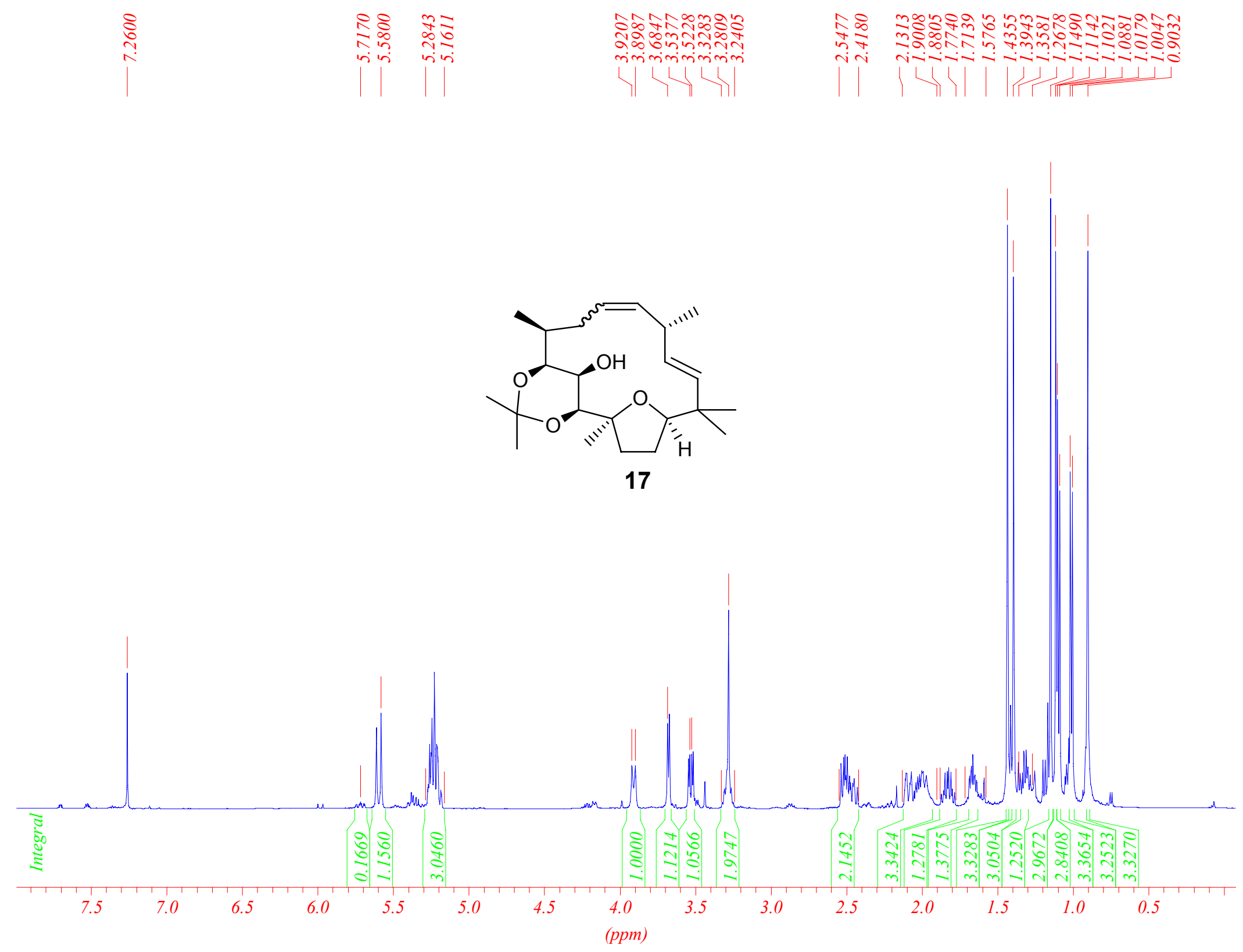




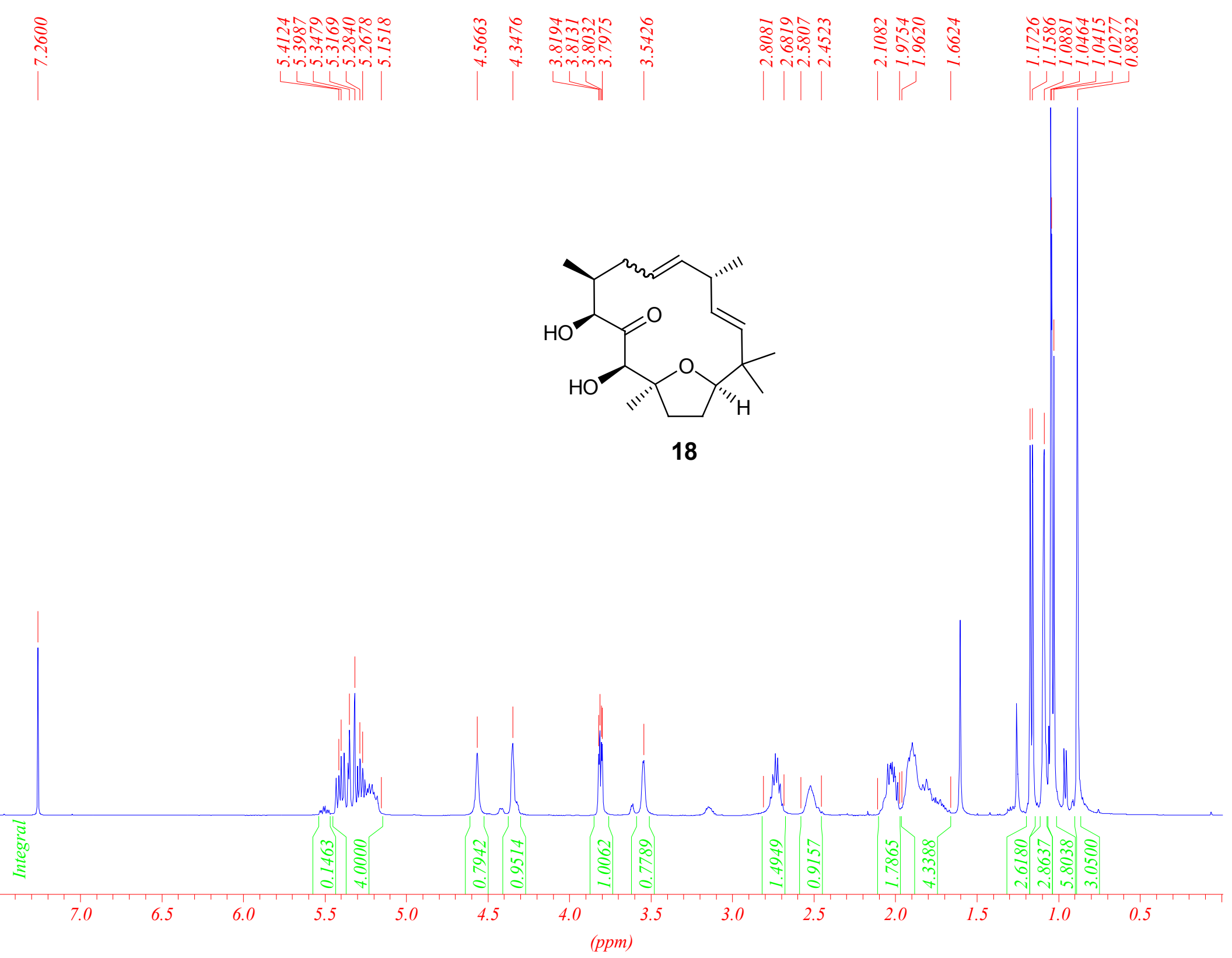




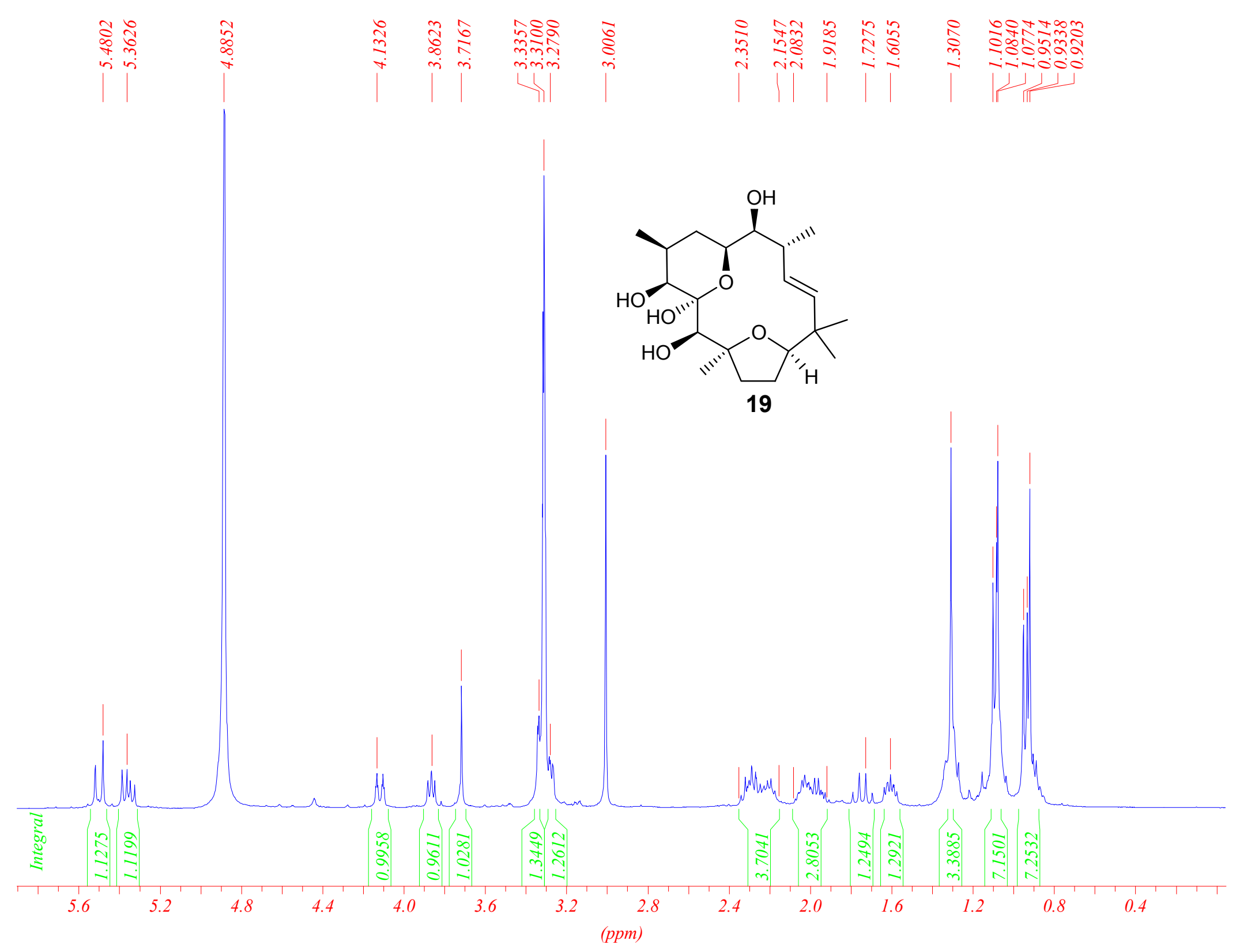




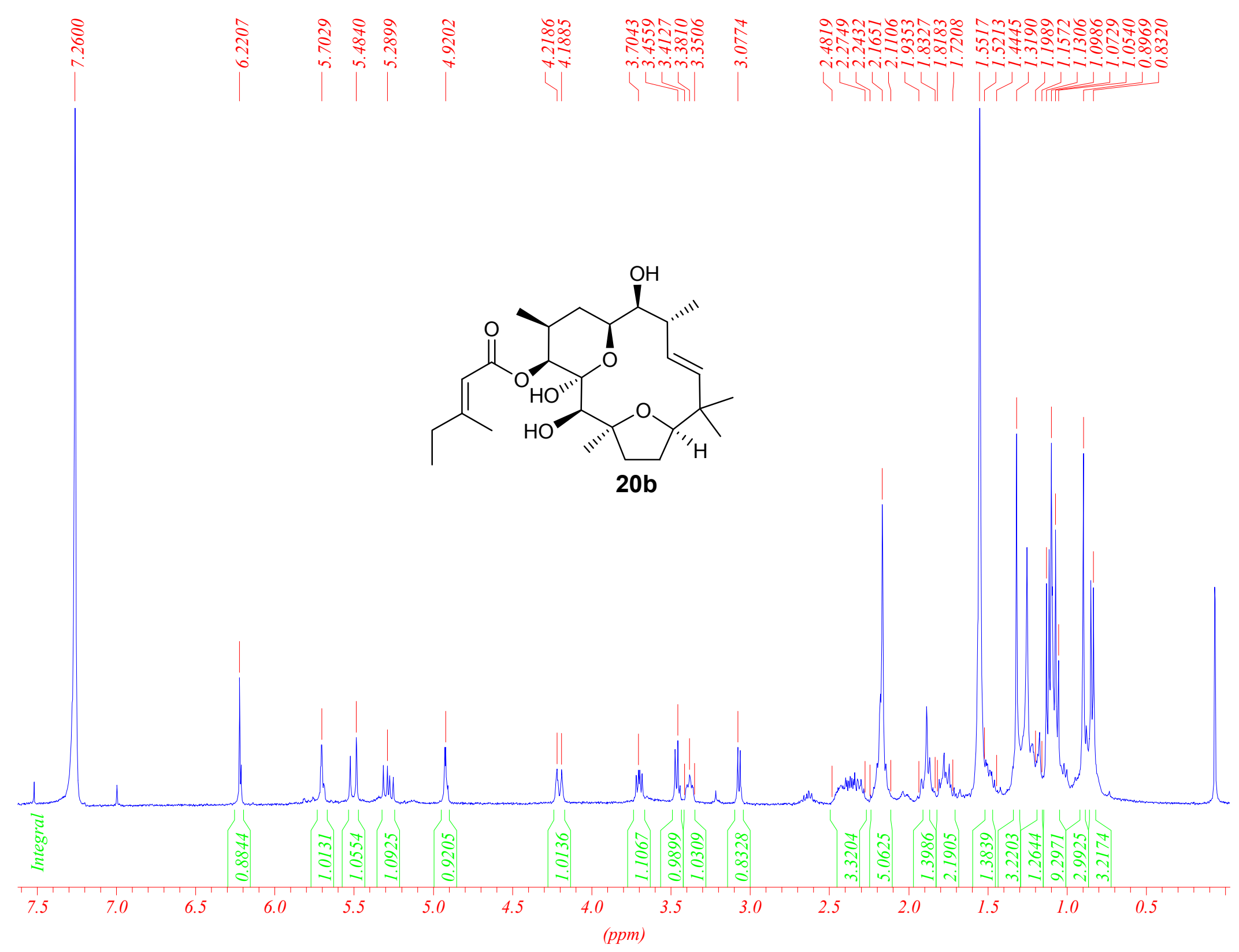




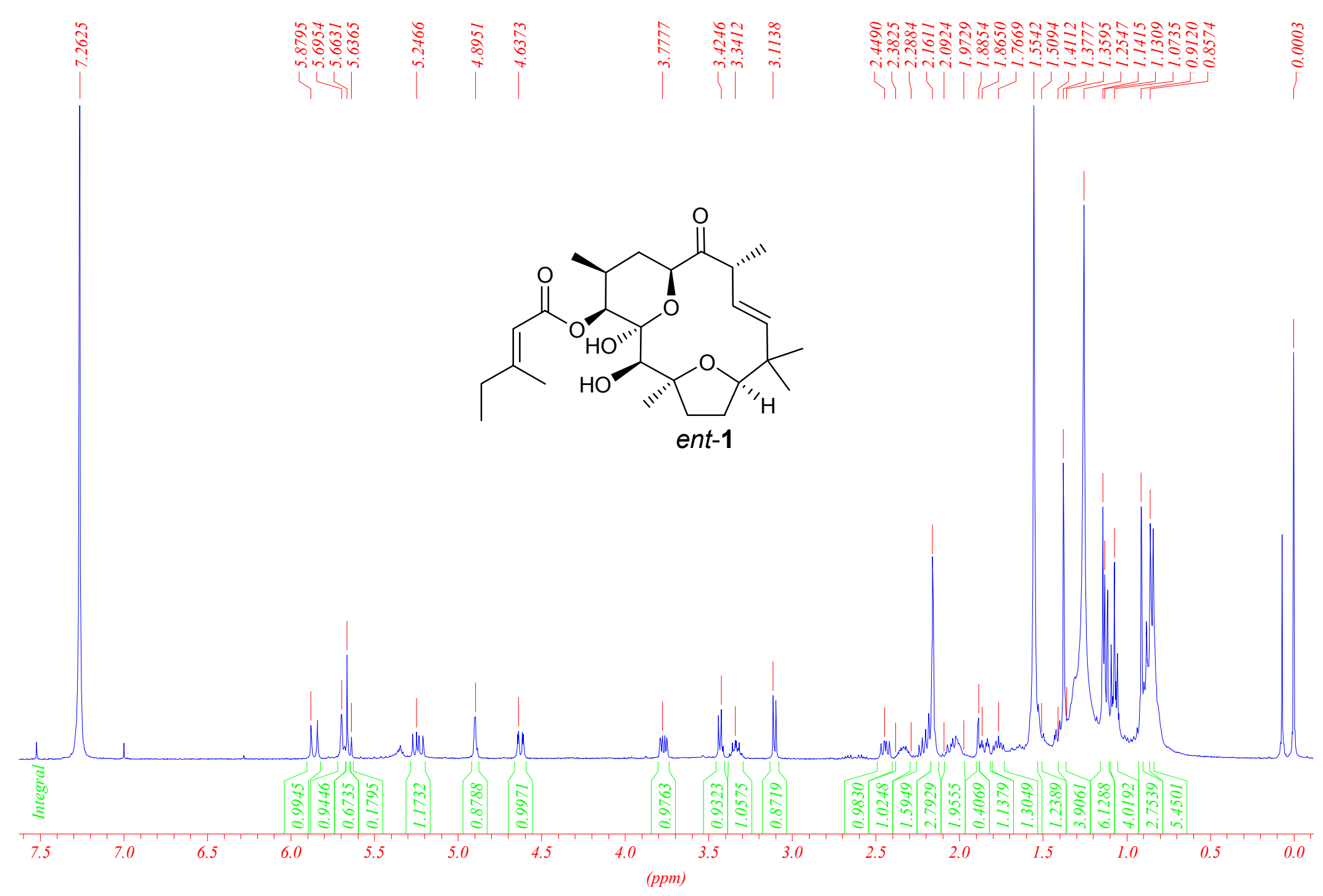




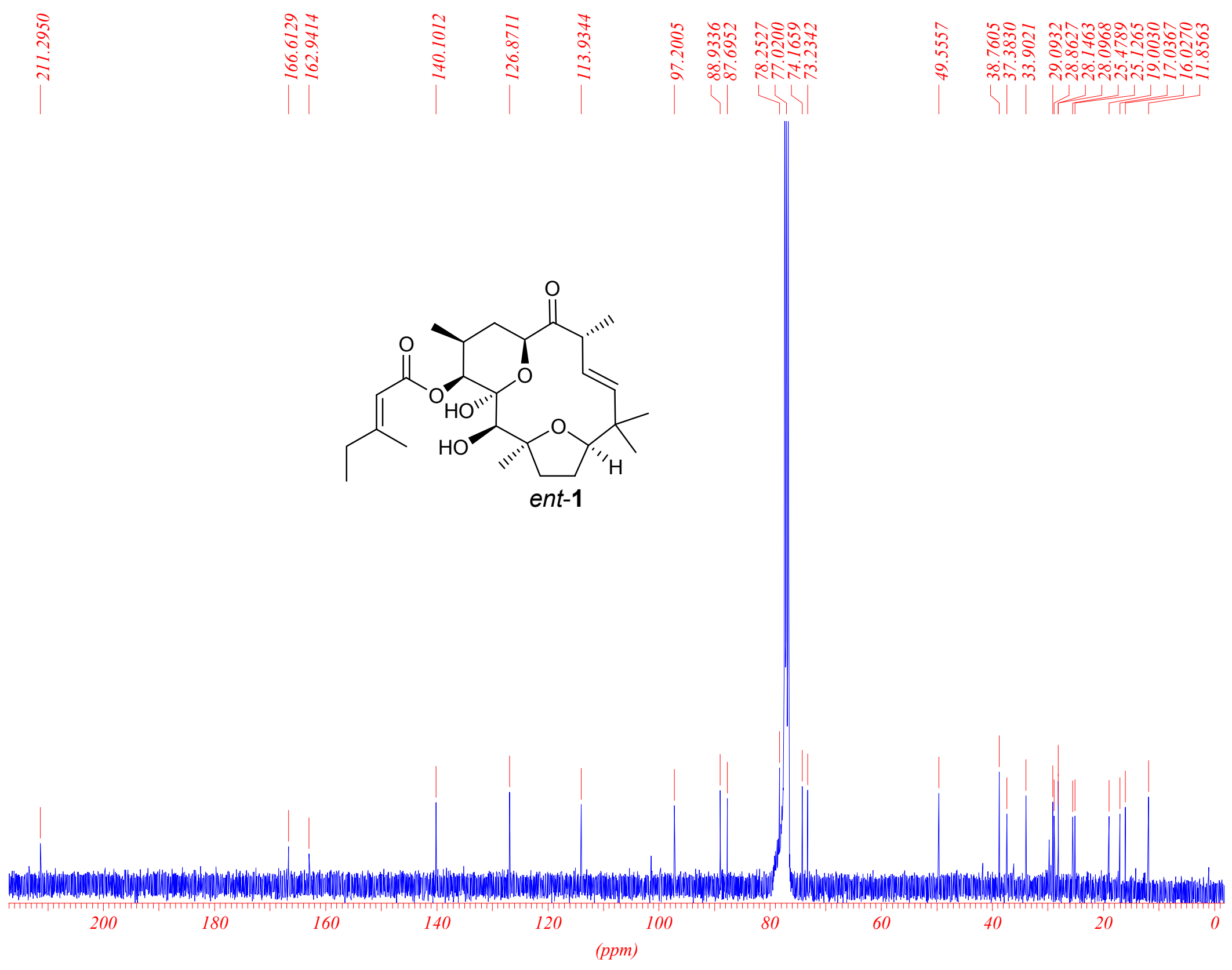



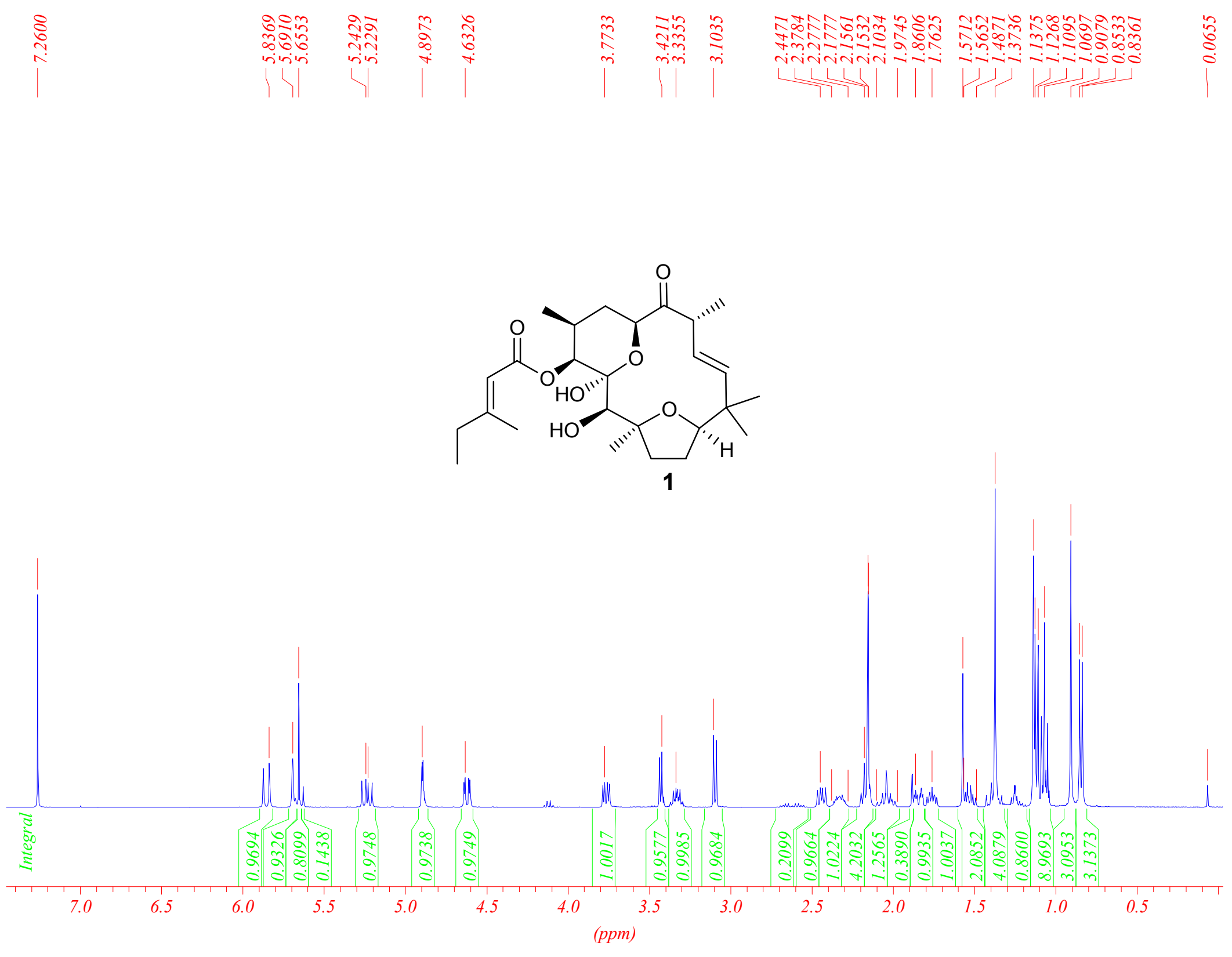

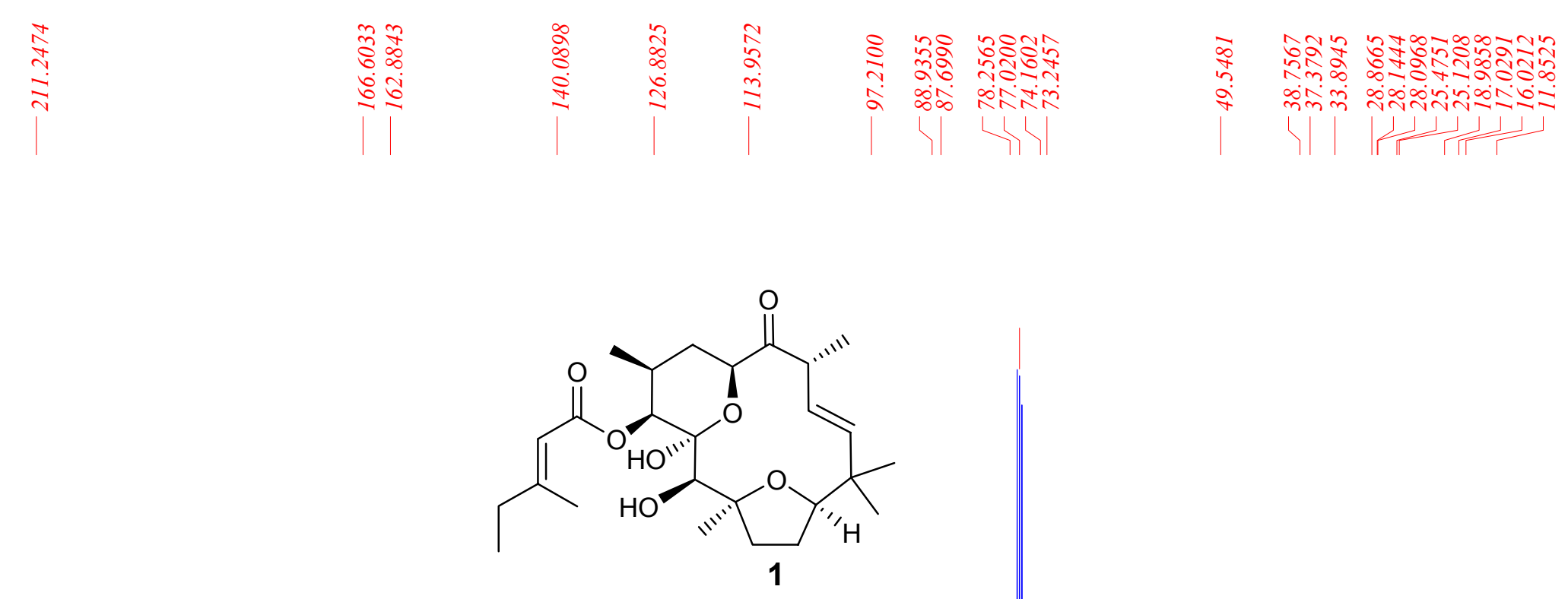